\title{
Autophagy is involved in recombinant Newcastle disease virus (rL-RVG)-induced cell death of stomach adenocarcinoma cells in vitro
}

\author{
XU-FENG BU ${ }^{1}$, MU-BING WANG ${ }^{1,2}$, ZHI-JIAN ZHANG ${ }^{2}$, YING-HAI ZHAO ${ }^{2}$, MI LI $^{2}$ and YU-LAN YAN ${ }^{3}$ \\ ${ }^{1}$ Department of General Surgery, Affiliated People's Hospital of Jiangsu University; \\ ${ }^{2}$ Clinical Medicine College of Jiangsu University; ${ }^{3}$ Department of Internal Medicine, \\ Affiliated People's Hospital of Jiangsu University, Zhenjiang, Jiangsu, P.R. China
}

Received April 8, 2015; Accepted May 11, 2015

DOI: $10.3892 /$ ijo.2015.3039

\begin{abstract}
Oncolytic viruses can kill malignant cells while sparing normal cells. Multiple pathways are involved in this action. The antitumor effects of viral infection on SGC-7901 and AGS cells were investigated. We measured endoplasmic reticulum stress and autophagy caused by the recombinant avirulent Newcastle disease virus (NDV) LaSota strain expressing the rabies virus glycoprotein (rL-RVG) and the NDV wild-type strain. The dose-response curves were analyzed using the MTT assay. The expression of RVG was detected by western blotting, RT-PCR and immunofluorescence analyses. Cell death and autophagy were observed using transmission electron microscopy, TUNEL and western blotting. Endoplasmic reticulum stress and the mitochondrial transmembrane potential were detected by western blotting and immunofluorescence, respectively. Immunofluorescence, western blot and RT-PCR analyses indicated that RVG gene and protein were expressed in SGC-7901 and AGS cells infected by rL-RVG. MTT and TUNEL analyses showed that the growth of SGC-7901 and AGS cells in the rL-RVGinfected group was significantly inhibited compared with the wild-type NDV-infected group $(\mathrm{p}<0.05)$. Western blot analysis indicated that rL-RVG and NDV induced increases in apoptosis, endoplasmic reticulum stress, and autophagy in the SGC-7901 and AGS cells. However, apoptosis and autophagy decreased in these cells after the application of the autophagy pathway inhibitor 3-MA or ATG-5-specific siRNA. Immunofluorescence analysis showed that the mitochondrial membrane potential collapsed. Taken together, these results indicate that the rL-RVG virus group is much more powerful compared with the NDV-infected group $(\mathrm{p}<0.05)$. rL-RVG and NDV are potent antitumor agents that induce autophagy.
\end{abstract}

Correspondence to: Dr Yu-Lan Yan, Department of Internal Medicine, Affiliated People's Hospital of Jiangsu University, Zhenjiang, Jiangsu, P.R. China

E-mail: ylyan2005@163.com

Key words: recombinant Newcastle disease virus, autophagy, apoptosis, endoplasmic reticulum stress, mitochondrial dysfunction

\section{Introduction}

In recent decades, an integrated approach to malignant cell treatment that includes surgery, chemotherapy (1), radiotherapy, gene therapy $(2,3)$ and immune therapy (4), has become a reasonable therapeutic strategy. Oncolytic virotherapy using agents such as Newcastle disease virus (NDV) is one of the new biological strategies for gene (2) and immune therapy (4-6) and has been tested against many different cancers, including gastric cancer (4), skin tumors (7) and solid cancers (8).

NDV, which is a member of the Paramyxoviridae family, is a non-segmented negative-strand RNA virus (NNSV). The NDV genes encode six major structural proteins, including nucleoprotein (NP), phosphoprotein $(\mathrm{P})$, matrix protein $(\mathrm{M})$, fusion protein $(\mathrm{F})$, hemagglutinin-neuraminidase $(\mathrm{HN})$ and large (L) RNA-dependent RNA polymerase, in the following order: 3'-NP-P-M-F-HN-L-5'. Oncolysis (9), apoptosis (10,11), and enhanced innate immunity $(4,12,13)$ are the known mechanisms by which NDV kills malignant cells.

The rabies virus (RV), which is a member of Rhabdoviridae family, is an enveloped, bullet-shaped virus that is also associated with host cell apoptosis $(13,14)$. Some clinical trials as early as the 1950s and 1960s demonstrated the effectiveness of RV in treating melanomatosis (15).

Autophagy is a catabolic and highly conservative cellular process. Its basic role is to recycle cellular components during nutritional starvation and other stressful conditions (16) and is considered a cytoprotective event (17). Despite its protective effects, autophagy can also induce a type of cell death (18) called 'type II programmed cell death' (19). Whether autophagy contributes to cell death or to protection during chemotherapy remains controversial (20). However, increasing evidence has demonstrated that autophagy represents cell death (21). Additionally, many chemicals, such as avicin D (22) and arsenic trioxide (23), as well as cellular stresses (24), and mitochondrial dysfunctions (25) can contribute to autophagy. Autophagy is a known potential anticancer strategy. Previous studies have shown that recombinant NDV-expressing rabies virus glycoprotein (rL-RVG) has the ability to spread from cell to cell without the help of trypsin (26), to alter its self-replication, and to induce cell death via the apoptosis pathway (27). 
The present study examined the contribution of autophagy to apoptosis induced by NDV or rL-RVG and raised a hypothesis regarding cross-talk among autophagy, apoptosis, mitochondrial dysfunction and endoplasmic reticulum stress (ERs).

\section{Materials and methods}

Materials. The NDV strain LaSota,rL-RVG, and anti-NDV antibody were provided by Harbin Veterinary Research Institute, Chinese Academy of Agricultural Sciences. The human cancer cell lines SGC-7901 and AGS were purchased from the Cancer Cell Repository (Shanghai Cell Bank, 2010-02-20) and ATCC (MD, USA), respectively. 3-[4,5-dimehyl-2-thiazolyl]2,5-diphenyl-2H-tetrazolium bromide (MTT) was purchased from Amresco (PA, USA). 3-Methyladenine (3-MA) and Hoechst 33342 were obtained from Sigma-Aldrich (St. Louis, MO, USA). The siRNA specific for human beclin-1 was from GenePharma (Shanghai, China). All PCR primers were purchased from Shanghai Sangon Biological Engineering Technology \& Services Co., Ltd. (Shanghai, China). TRIzol and Lipofectamine 2000 were from Invitrogen (CA, USA). Rabbit polyclonal anti-caspases 3, 8 and 9, anti-bax, antibeclin-1, anti-caspase 12, anti-HSP90, and anti-cytochrome $c$; and mouse monoclonal anti-Bcl-2 and anti-grp 78 antibodies were from Boster (Wuhan, China). Rabbit monoclonal antiLC3 antibody was from Epitomics (Burlingame, CA, USA), and mouse monoclonal anti-rabies virus was obtained from Santa Cruz (CA, USA). HRP-conjugated goat anti-rabbit, HRP-conjugated goat anti-mouse, and FITC-conjugated goat anti-mouse antibodies were purchased from CWBio (Shanghai, China). HRP-conjugated rabbit anti-chicken antibody was from EarthOx Life Science (Millbrae, CA, USA), and Cy3-conjugated rabbit anti-chicken antibody was purchased from KPL (CA, USA). The PVDF membrane and Luminata were provided by Millipore (MA, USA). DMEM, trypsin, and EDTA-2Na were offered by Gibco (NY, USA). Fetal bovine serum (FBS) was supplied by Hyclone (UT, USA). A mitochondrial transmembrane potential analysis kit was from KeyGen Biotech (Nanjing, China). All other supplies for cell culture were obtained from Costar Corning (NY, USA).

Cell culture and interference test. SGC-7901 and AGS cells were maintained in DMEM medium with $10 \%$ (v/v) FBS, antibiotics $(100 \mathrm{U} / \mathrm{ml}$ penicillin and $100 \mathrm{U} / \mathrm{ml}$ streptomycin) at $37^{\circ} \mathrm{C}$ with $5 \% \mathrm{CO}_{2}$ and $100 \%$ humidity. When the cells reached $\sim 50-70 \%$ confluence, the cells were infected with NDV or rL-RVG.

3-MA application. When the SGC and AGS cells grown in 6 -well plates reached $\sim 50-70 \%$ confluence, the cells were treated with $2.5 \mathrm{mM}$ 3-MA. The next day, the cells were infected with NDV and rL-RVG at a multiplicity of infection (MOI) of 10. At $24 \mathrm{~h}$ after being infected, the cells were harvested and analyzed by western blotting.

siRNA application. When the SGC and AGS cells grown in 6 -well plates reached $\sim 50-70 \%$ confluence, the cells were transfected with $50 \mathrm{nM}$ siRNA (beclin-1) according to the manufacturer's instructions. The next day, the cells were infected with NDV and rL-RVG at a MOI of 10. At $24 \mathrm{~h}$ after being infected, the cells were harvested and analyzed by western blotting.

MTT analysis. SGC-7901 or AGS cells $\left(1 \times 10^{4}\right)$ were cultured in 96-well plates for $24 \mathrm{~h}$ with $10 \% \mathrm{FBS}$ at $37^{\circ} \mathrm{C}$ with $5 \% \mathrm{CO}_{2}$. On the second day, the cells were incubated in serum-free DMEM with rL-RVG or NDV at concentrations of $10^{-2}, 10^{-3}$, $10^{-4}$ and $10^{-5}$. After $1 \mathrm{~h}, 10 \%$ FBS was added to each well, and then the cells were cultured as described previously, with a phosphate-buffered saline (PBS) group as the negative control. On the third day, each well was treated with $20 \mu 1$ MTT (5 mg/ml, PBS) and incubated for an additional $4 \mathrm{~h}$. Then, $150 \mu \mathrm{l}$ of DMSO was added into each well, and the cells were shaken for $10 \mathrm{~min}$. Finally, the absorbance was measured in triplicate using a standard spectrophotometer. The doseresponse curve for cell survival was made based on data from the MTT assay. Simultaneously, the morphological changes in the infected cells were monitored under a microscope.

Immunofluorescence analysis. Cells were cultured in 24-well plates for $24 \mathrm{~h}$ as previously described, infected with NDV or rL-RVG at a MOI of 10, or treated with PBS as a negative control. Then, at $24 \mathrm{~h}$ post-infection, the cells were fixed in $4 \%$ paraformaldehyde at $4^{\circ} \mathrm{C}$ overnight, followed by immunofluorescence staining with antibodies against NDV and RV and Hoechst 33342 staining. These stained SGC and AGS cells were monitored using immunofluorescence microscopy.

RT-PCR analysis. The cells were cultured and infected as described previously. At $24 \mathrm{~h}$ after infection, total RNA was extracted from the cultured cells using TRIzol reagent. First-strand cDNA synthesis was performed using oligo(dT) primers and M-MLV reverse transcriptase. The primer set for the NDV HN gene, the RV G gene and the human GAPDH gene are shown in Table I. The RT-PCR protocol was as follows: an initial denaturation at $94^{\circ} \mathrm{C}$ for $5 \mathrm{~min}$, followed by 30 cycles at $94^{\circ} \mathrm{C}$ for $30 \mathrm{sec}$, annealing at $53^{\circ} \mathrm{C}(\mathrm{RVG})$ or $55^{\circ} \mathrm{C}$ (NDV and GAPDH) for $30 \mathrm{sec}$, and extension at $72^{\circ} \mathrm{C}$ for $30 \mathrm{sec}$, with a final extension at $72^{\circ} \mathrm{C}$ for $10 \mathrm{~min}$. Then, $5 \mu \mathrm{l}$ of each PCR product was loaded onto $1 \%$ agarose gels for electrophoresis and visualized with ethidium bromide. The resulting bands were analyzed using Quantity One software (Bio-Rad). The primers for PCR are shown in Table I.

Western blot assay. SGC and AGS cells with or without treatment were lysed in RIPA lysis buffer with a protease inhibitor cocktail (Santa Cruz). The protein concentration was measured using a BCA kit (Thermo Fisher Scientific, USA). An equal amount of protein from each sample was loaded onto a $10 \%$ polyacrylamide gel and separated by electrophoresis. Then, the proteins were transferred to a polyvinylidene difluoride (PVDF) membrane (Millipore, CA, USA). The membrane was blocked for $1 \mathrm{~h}$ in $5 \%$ BSA. Then, the membrane was incubated with primary antibodies against specific proteins (i.e., caspases 3, 8 and 9, bcl-2 and bax for apoptosis; NDV and RVG for infection, Beclin-1 and LC-3 for autophagy; anti-HSP90, anti-cytochrome $c$ and anti-grp 78 for endoplasmic reticulum stress; and beta-actin as a control) and then incubated with HRP-conjugated secondary antibodies. The protein bands were scanned using a Typhoon 
Table I. PCR primers.

\begin{tabular}{llll}
\hline Primer & & Sequence & Product size (bp) \\
\hline rL-RVG & Upstream & 5'-AGCCGATGCTCACTACAAG-3' & 175 \\
& Downstream & 5'-CTGGAGGAGGGATGATTGC-3' & 462 \\
NDV & Upstream & 5'-CTGGACGGTTTGGTGGGAA-3' & - \\
& Downstream & 5'-TAATGCGACTGCGGGATGTG-3' & - \\
GAPDH & Upstream & 5'-CAAGGTCATCCATGACAACTTTG-3' & \\
& Downstream & 5'-GTCCACCACCCTGTTGCTGTAG-3' \\
\hline
\end{tabular}

Table II. MTT results of the cellular dose-response curve for SGC cells after $24 \mathrm{~h}$ of infection.

\begin{tabular}{lccrr}
\hline Dilution & rL-RVG & NDV & t-value & p-value \\
\hline $10^{1}$ & $0.18656 \pm 0.029626$ & $0.283727 \pm 0.026238$ & 3921 & 0.017 \\
$10^{2}$ & $0.312080 \pm 0.04746$ & $0.55666 \pm 0.024781$ & 11.521 & $<0.001$ \\
$10^{3}$ & $0.54400 \pm 0.037857$ & $0.62300 \pm 0.028032$ & 3.461 & 0.02 \\
$10^{4}$ & $0.56130 \pm 0.038402$ & $0.61522 \pm 0.61522$ & 4.971 & 0.08 \\
\hline
\end{tabular}

9400 Variable Mode Imager (Amersham Biosciences, UK) and detected by Pierce ECL Plus Substrate (Thermo Fisher Scientific)

Transmission electron microscopy (TEM). Standard TEM was performed to monitor the ultrastructure of the cells. Cells were infected with virus as described previously. At $24 \mathrm{~h}$ after infection, the cells were fixed and embedded in $4 \%$ paraformaldehyde and $2.5 \%$ glutaraldehyde. Thin sections were cut and examined at $200 \mathrm{kV}$ using an $\mathrm{H}-600$ transmission electron microscope. Autophagy, as defined by the presence of double-membraned vacuoles; apoptosis, as characterized by chromatin margination, pyknosis, and apoptotic bodies; and endoplasmic reticulum swelling were all observed.

TUNEL assay. Cells were cultured in 24-well plates with slides and $10 \%$ FBS DMEM at $37^{\circ} \mathrm{C}$ with $5 \% \mathrm{CO}_{2}$. Then, the cells were infected with rL-RVG and NDV within the logarithmic growth phase and fixed in $4 \%$ paraformaldehyde. After fixing, the cells were stained according to the manufacturer's instructions. The slides were observed and imaged under an optical microscope. The apoptosis index (AI) was calculated as the number of apoptotic cells/(the number of apoptotic cells + the number of non-apoptotic cells) x $100 \%$.

Detection of mitochondrial membrane potential (MMP). JC-1 fluorescence dye was used to determine the mitochondrial membrane potential. Cells were cultured in 24-well plates and treated with NDV or rL-RVG as described above for $24 \mathrm{~h}$, followed by staining with $\mathrm{JC}-1\left(2.5 \mu \mathrm{g} / \mathrm{ml}\right.$ at $37^{\circ} \mathrm{C}$ for $30 \mathrm{~min})$. The cells were monitored using fluorescence microscopy with excitation wavelengths at $527 \mathrm{nM}$ for green and at 590-600 $\mathrm{nM}$ for red. The changes in the MMP could be accurately assessed by comparing the ratios of 590-600 nM (red)/527 nM (green).
Statistical analysis. The data comparisons were performed using one-way analysis of variance (ANOVA) in SPSS V17.0 software. Differences were considered statistically significant at $\mathrm{p}<0.05$. All experiments were repeated at least three times.

\section{Results}

Expression of viral genes and proteins in infected stomach adenocarcinoma cells. The expression of viral proteins was monitored by fluorescence microscopy. Almost all of the SGC and AGS cells that were infected with NDV expressed the NDV HN protein, and almost all of the SGC and AGS cells infected with rL-RVG expressed both the NDV HN protein and RVG protein, while neither of these proteins was present in the control group. RVG and NDV protein expression was upregulated in the rL-RVG-infected group compared with the NDV-infected group, as shown in Fig. 1A and B. Western blot analysis confirmed these results, as shown as Fig. 1C. The PCR products of the NDV HN and RVG genes were detected to assess NDV HN and RVG mRNA expression in infected SGC and AGS cells. The results showed that the RVG gene (175 bp) was expressed in SGC and AGS cells infected with rL-RVG and that the NDV HN gene (462 bp) was expressed in the SGC and AGS cell infected groups. In contrast, neither the RVG gene nor the NDV HN gene was expressed in the control group (Fig. 1D).

The proliferation changes of SGC and AGS cells infected with $r L-R V G$ and NDV. The dose-response curves for rL-RVG and NDV in SGC cells were monitored by MTT. After 24 or $48 \mathrm{~h}$ of rL-RVG or NDV infection, the infected SGC cells were assessed by MTT assay. SGC cell viability decreased with an increase in virus concentration or in incubation time. When the cells were infected simultaneously with NDV and rL-RVG, the OD of MTT increased in both the NDV- and rL-RVG- 
A

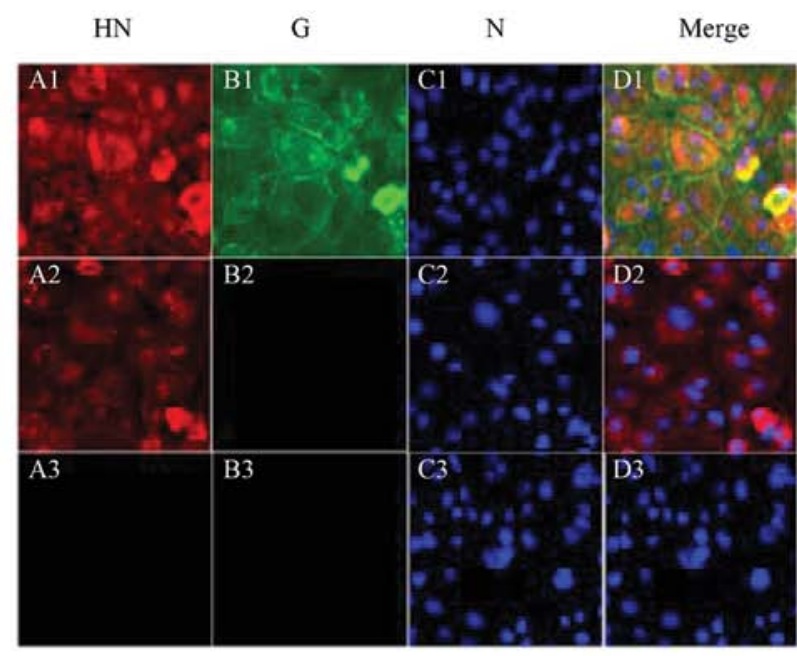

B

$\mathrm{HN}$

G

$\mathrm{N}$

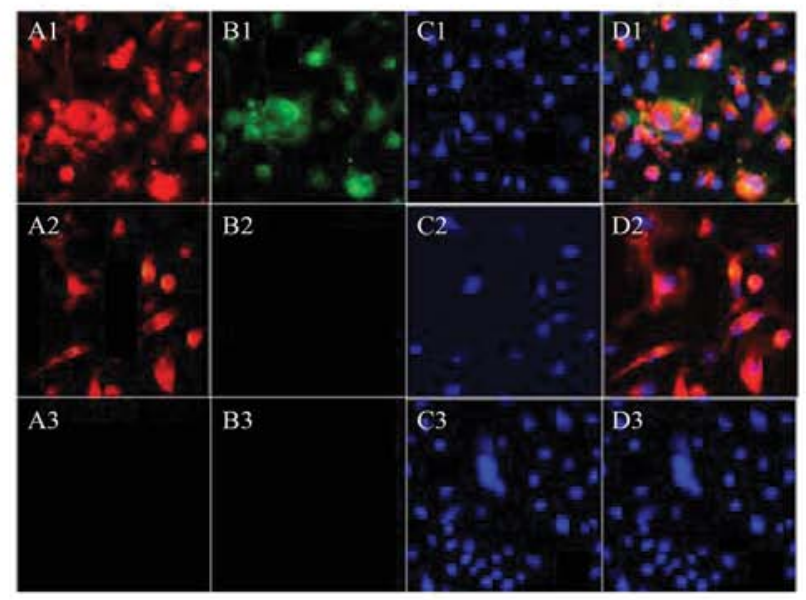

C

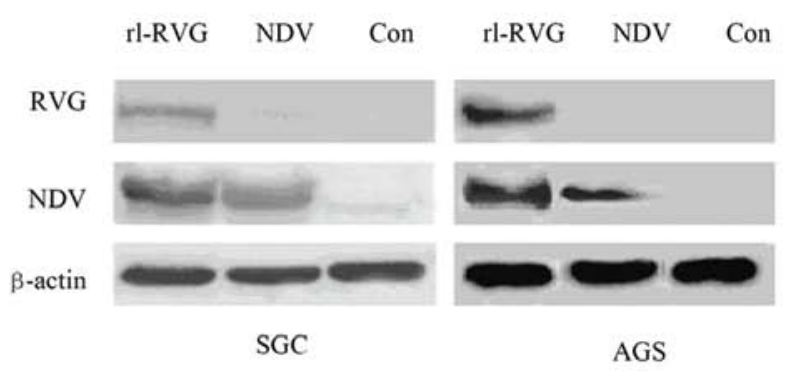

D

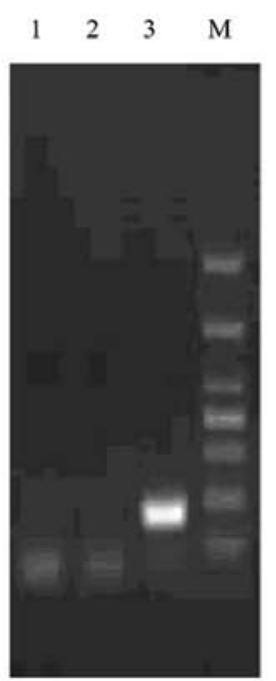

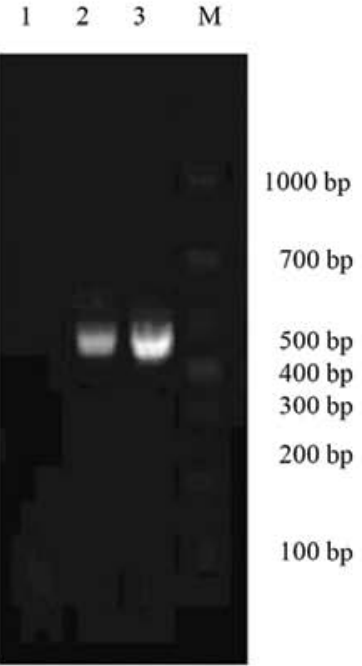

Figure 1. Expression of viral proteins and genes in infected SGC and AGS cells. RVG and NDV protein expression was monitored by immunofluorescence (x200 magnification) (A) for SGC and (B) for AGS. The RVG protein (green) was only expressed in the rL-RVG-infected group, while the NDV protein (red) was expressed in both the rL-RVG- and NDV-infected groups. Neither protein was expressed in the control group. (C) RVG and NDV protein expression in SGC cells and in AGS cells was detected by western blotting. The RVG protein was only present in the rL-RVG-infected group, and the NDV protein was expressed in both the rL-RVG- and NDV-infected groups. Neither protein was expressed in the PBS group.(D) NDV and RVG mRNA expression. Lane 1, PBS group; lane 2, NDV-infected group; lane 3, rL-RVG-infected group; M, marker. (B) NDV HN mRNA expression. Lane 1, PBS group; lane 2, NDV-infected group; lane 3, rL-RVG-infected group; M, marker.

infected groups as the virus dilution decreased, and at the $10^{3}$ dilution, the dose-response curve reached a plateau compared with the control group. Simultaneously, the OD of MTT in the rL-RVG-infected group was weaker compared with that in the NDV-infected group, suggesting that the rL-RVG-infected group had a greater inhibition ratio. The inhibition ratio increased over time after infection. Thus, the inhibition ratio caused by NDV and rL-RVG infection was dependent on both time and dose. The OD values of MTT in SGC cells after $24 \mathrm{~h}$ are shown in Fig. 2A and Table II. Additionally, the morphological changes in the infected or uninfected cells, as observed by microscopy, are shown in Fig. 2B; the cells had a greater decrease in size in the rL-RVG-infected group compared with the NDV-infected group, and the number of smaller cells was higher in the rL-RVG-infected group compared with the NDV-infected group. No changes were observed in the PBS group. $r L-R V G$ and NDV infection affected the ultrastructure of $S G C$ and AGS cells. We monitored the cells by TEM to assess the ultrastructure of the cells after infection directly. The cells that were infected with NDV or rL-RVG showed increased autophagy (black arrow), apoptosis (white arrow) and ERs (white triangle), with a larger effect observed in the L-RVG group compared with the NDV-infected group, as shown in Fig. 3.

$N D V$ and $r L-R V G$ induce apoptosis in SGC and AGS cells. Apoptosis was monitored by TUNEL assay; apoptosis in the virus-infected SGC cells was obvious compared with the control cells, and the number of apoptotic cells in the rL-RVG-infected groups was greater than that in the NDV-infected group, as shown in Fig. 4A. Furthermore, to assess the apoptotic cell death pathway caused by NDV and rL-RVG infection, the expression of the apoptosis-associated 
A

\section{Dose-effect curve}

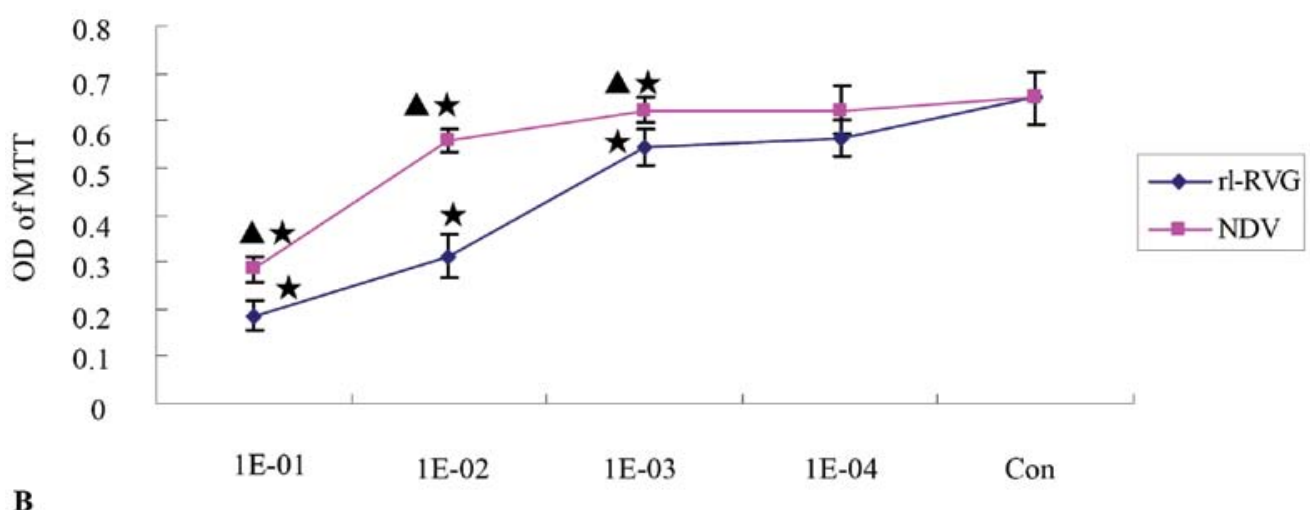

B

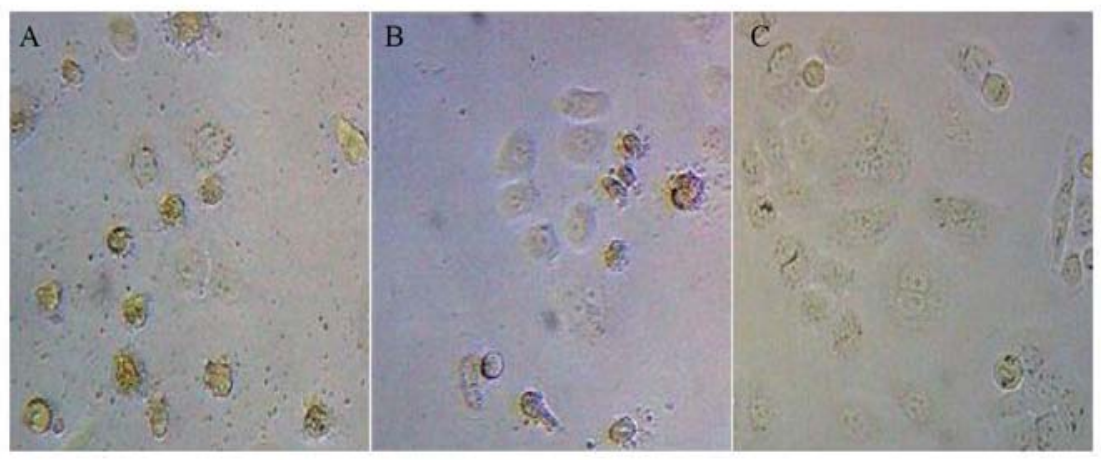

Figure 2. Proliferation changes in SGC cells after viral infection. (A) Dose-response curve of SGC cells after viral infection at $24 \mathrm{~h}$. The OD of MTT after dilution $(\mathrm{n}=5)$. The cells infected with $\mathrm{rL}-\mathrm{RVG}$ for $24 \mathrm{~h}$ showed significantly decreased absorbance when compared with OD of the NDV-infected group $(\mathrm{p}<0.05)$. A significant difference was observed between different dilutions of the same virus ( $\left.{ }^{\mathrm{p}} \mathrm{p}<0.05\right)$. (B) Images of SGC cells infected with virus at $24 \mathrm{~h}$ using microscopy (x200 magnification). (a) rL-RVG-infected group (10-2); (b) NDV-infected group (10-2); (c) control group. The cells infected with rL-RVG decreased in size compared with those of the NDV-infected group, and the number of smaller cells was higher in the rL-RVG-infected group compared with that of the NDV-infected group. No changes were observed in the control group.
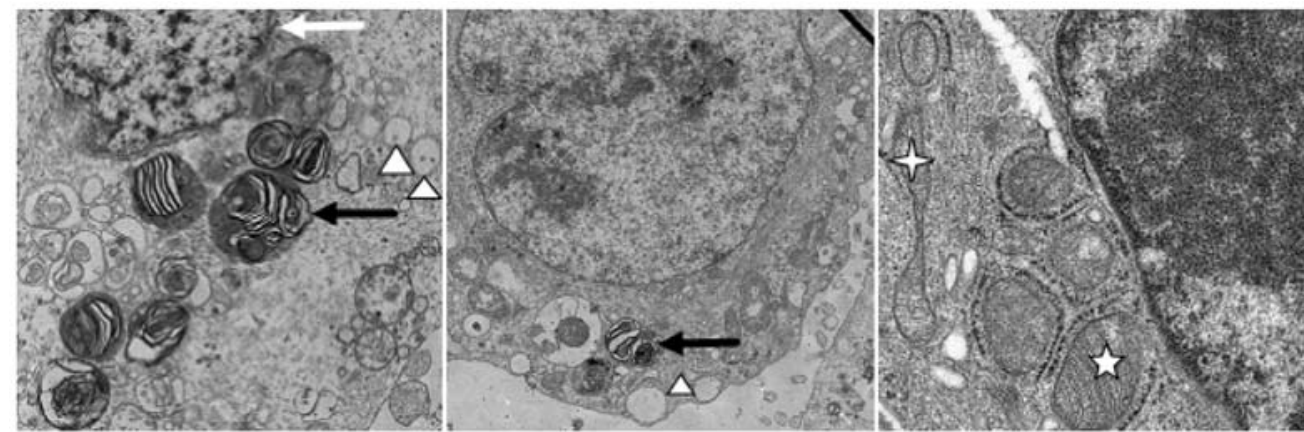

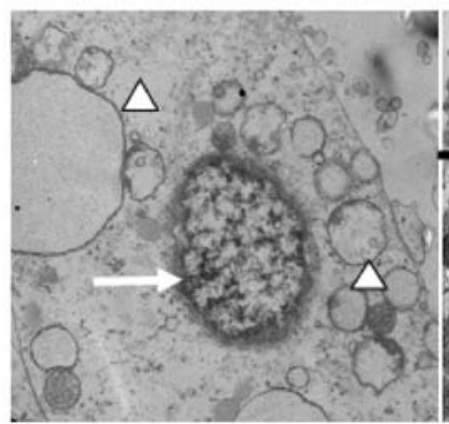

rL-RVG

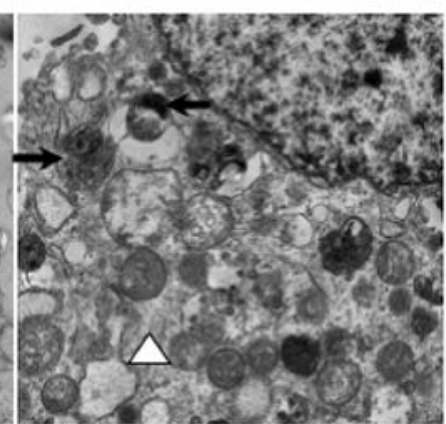

NDV

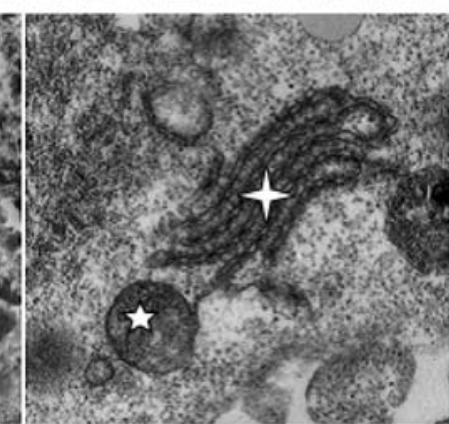

Con

Figure 3. The ultrastructure of the SGC cells after viral infection. The black arrow shows autophagy, white arrows indicate apoptosis, and white triangles show ERs. Additionally, white stars and pentagons indicate the endoplasmic reticulum and mitochondria in the PBS group, respectively. Autophagy, apoptosis and ERs in cells from the rL-RVG-infected group significantly increased compared with those processes in cells from the NDV-infected group. No effect was observed in the PBS group. 

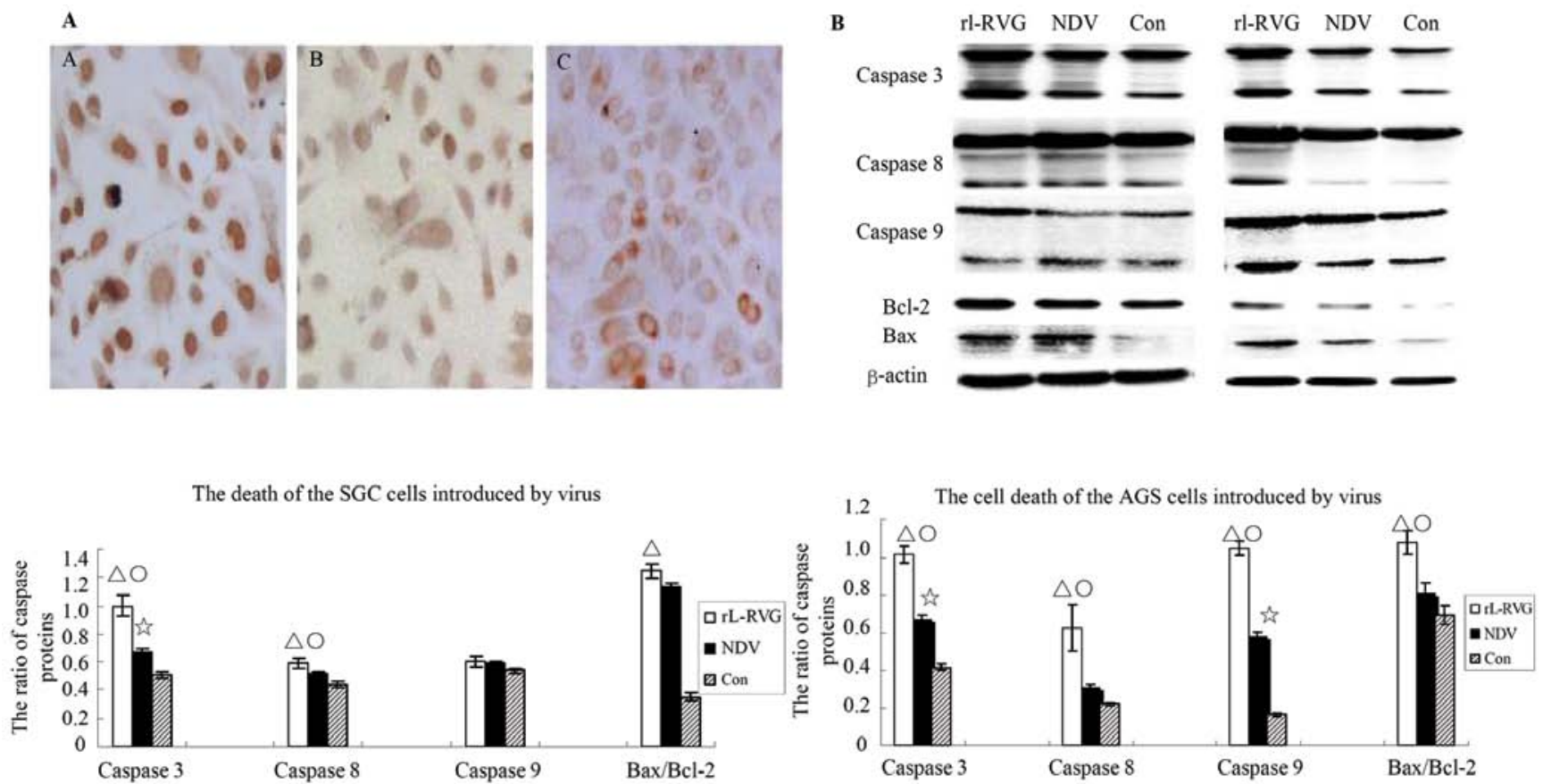

Figure 4. Apoptosis and its associated protein expression in SGC and AGS cells at $24 \mathrm{~h}$ after infection. (A) Apoptosis of infected SGC cells, as measured by TUNEL staining. Apoptosis of virus-infected cells was obvious compared with the controls. The apoptotic cells in the rL-RVG-infected groups were more abundant compared with those in the NDV-infected group. (B) The expression of apoptosis-associated proteins in SGC and AGS cells, as detected by western blotting. The proteins cleaved caspase 3 and 8 and bax/bcl-2 in the rL-RVG-infected group had higher expression levels compared with those in the other two groups $\left({ }^{\circ, \wedge} \mathrm{p}<0.05\right)$; these proteins also had higher expression levels in the NDV-infected group compared with the controls ( $\left.{ }^{\star} \mathrm{p}<0.05\right)$. No significant differences were observed in the following pairs: in the SGC cells, the cleaved caspase 8 protein levels did not significantly differ between the NDV-infected group and the control group, the cleaved caspase 9 protein levels did not significantly differ among the three groups, and the protein ratio of bax to bcl-2 did not significantly differ between the NDV-infected group and the control group; in the AGS cells, the cleaved caspase 8 protein levels did not significantly differ between the NDV-infected group and the control group, and the protein ratio of bax of bcl2 did not significantly differ between the NDV-infected group and the control group $(\mathrm{p}>0.05)$.

proteins caspase 3,8 and 9, bcl-2, and bax in the SGC and AGS cells was examined routinely at $24 \mathrm{~h}$ after being infected with NDV or rL-RVG. Accumulations of cleaved caspase 3,8 and 9 and of bax/bcl-2 were found in SGC and AGS cells infected with virus. The expression levels of cleaved caspase 3 and 8 and bax/bcl2 proteins were upregulated in the rL-RVG-infected group compared with the other two groups. The expression levels of these proteins were higher in the NDV-infected group compared with those in the control group. In the SGC cells, the expression levels of cleaved caspase 8 protein did not differ between the NDV-infected group and the control group. Additionally, the expression levels of cleaved caspase 9 protein did not differ among all the three groups, and the protein ratio of bax to bcl2 did not differ between the NDV-infected group and the control group. In the AGS cells, the expression levels of cleaved caspase 8 protein did not differ between the $\mathrm{NDV}$-infected group and the control group, and the protein ratio of bax to bcl-2 did not differ between the NDV-infected group and the control group, as shown in Fig. 4B.

$N D V$ and $r L-R V G$ induce significant autophagy in SGC and AGS cells. Because TEM analysis indicated that autophagy significantly increased after SGC cells were infected with virus, we detected the autophagy activity of cells with or without NDV or rL-RVG infection. The ratio of lipid-bound LC3-II, which is converted to LC3-I, the soluble LC3-I is associated with the formation of autophagosomes and can indicate autophagic activity. In a preliminary experiment, we found that the autophagic activity peaked at least two times after infection from $30 \mathrm{~min}$ to $48 \mathrm{~h}$. The first peak occurred at the $3 \mathrm{rd}$ hour after infection, while the second peak occurred at $24 \mathrm{~h}$ after infection (data not shown). Considering that autophagy protects against infection, we suggested that the second peak time contributes to cell death. In addition to monitoring the ratio of LC3-II to LC3-I in cells at $24 \mathrm{~h}$ post-infection, we also monitored another autophagy marker, beclin-1, in these cells. As shown in Fig. 5. the expression of the autophagy-associated protein beclin-1 and LC3 in the SGC cells of the rL-RVGinfected group showed a significant difference compared with the other two groups $\left({ }^{\triangle},{ }^{\circ} \mathrm{p}<0.05\right)$; the expression of the autophagy-associated protein in the NDV-infected group showed a significant difference compared with the control group $\left({ }^{*} \mathrm{p}<0.05\right)$. The trend is the same in the expression of beclin-1 and LC3 in the AGS cells and the same trend exists among the three group. However, beclin-1 in the AGS cells showed no significant differences between the rL-RVG and the NDV-infected group $(\mathrm{p}>0.05)$.

$N D V$ and $r L-R V G$ cause endoplasmic reticulum stress in the $S G C$ cells. Recent evidence has demonstrated that ERs is a type of trigger for autophagy. In the present study, TEM images showed infected cells with endoplasmic reticulum swelling, indicating that the SGC cells had ERs. Therefore, we monitored the expression of the following proteins associated with ERs: grp-78, HSP-90 and cytochrome $c$. The expression of the grp-78, and HSP-90 proteins in SGC cells showed significant 

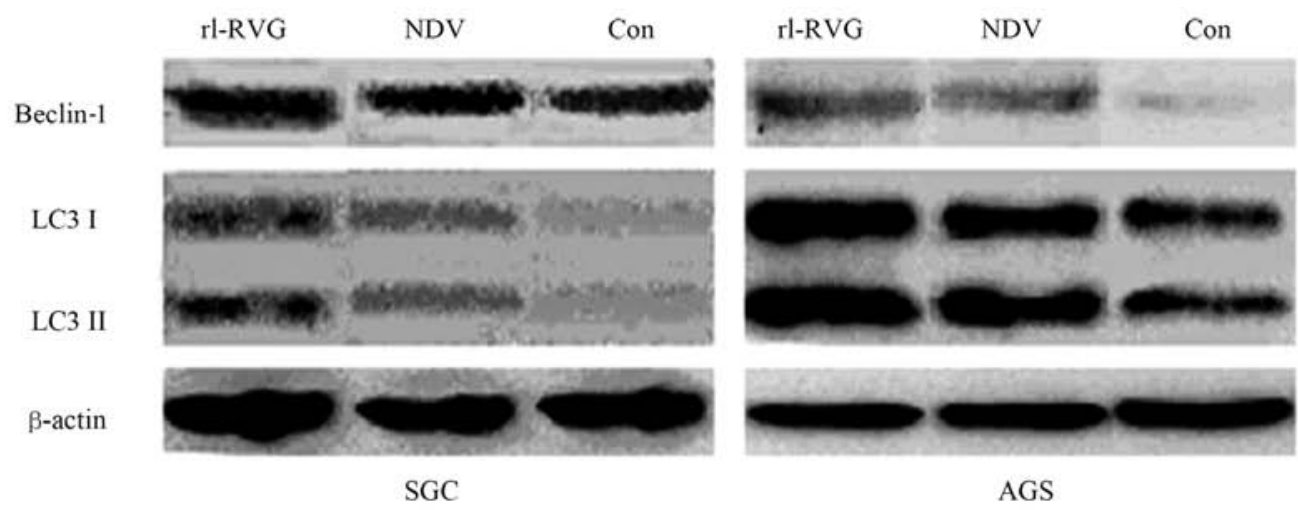

AGS

The expression of autophagy associated protein in SGC cells after infection

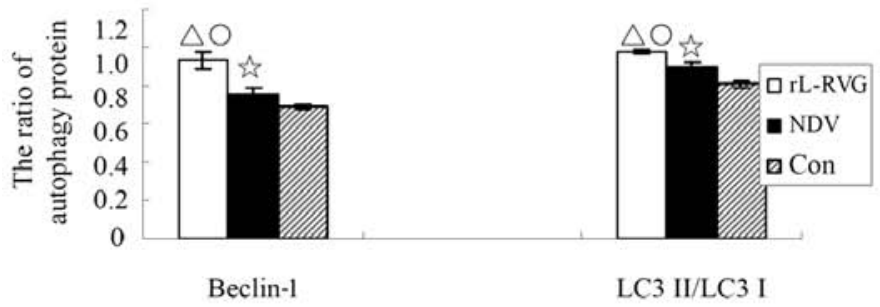

The expression of autophagy associated protein in AGS cells after infection

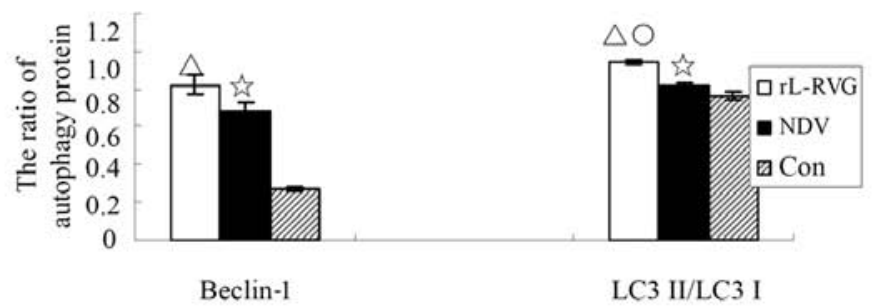

Figure 5. NDV- and rL-RVG-induced autophagy of SGC and AGS cells. The expression of the autophagy-associated proteins beclin-1 and LC3 in the NDVinfected group significantly differed compared with that of the control group $\left({ }^{*} \mathrm{p}<0.05\right)$ and compared with that of the rL-RVG-infected group and the NDV-infected group $\left({ }^{\circ} \mathrm{p}<0.05\right)$. The expression of these autophagy-associated proteins in the rL-RVG-infected group significantly differed compared with that of the control group $\left({ }^{\wedge} \mathrm{p}<0.05\right)$.

differences among the three groups $(\stackrel{\Delta, 4,0}{, 4}<0.05)$, and the expression of the cytochrome $c$ protein in the control groups was higher compared with that in the two infected groups $\left({ }^{\triangle},{ }^{\star} p<0.05\right)$. However, no significant difference was observed between the rL-RVG and NDV-infected groups $(p>0.05)$. These results suggested that the infected cells remained under ERs.

Autophagy contributes to SGC and AGS apoptosis induced by $N D V$ and $r L-R V G$. Recent research has indicated that autophagy can have both cytoprotective and cytotoxic effects $(28,29) .3-$ MA, which is an inhibitor of autophagy, was administered to SGC and AGS cells with or without NDV or rL-RVG infection to determine whether autophagy contributes to the apoptosis of NDV- and rL-RVG-infected cells. The expression of the apoptosis-associated proteins caspase 3, 8 and 9 and calpain 1, which is related to autophagy and apoptosis (30), decreased in SGC and AGS cells with 3-MA treatment relative to control cells without 3-MA treatment. The effect was greater in the rL-RVG-infected groups than in the NDV-infected groups, as shown in Fig. 7A. Because 3-MA is a non-specific autophagy suppressor, it inhibits both PI3K-III (an autophagy inducer) and PI3K-I (an autophagy suppressor). We silenced beclin-1, which is an autophagy regulator, to confirm the 3-MA results. The potency of the siRNA treatment was determined by western blotting, as shown in Fig. 7B. We found that the expression of the beclin-1 protein decreased significantly in SGC cells upon beclin-1 siRNA treatment. Therefore, we monitored the apoptosis-associated proteins caspase 3, 8 and 9

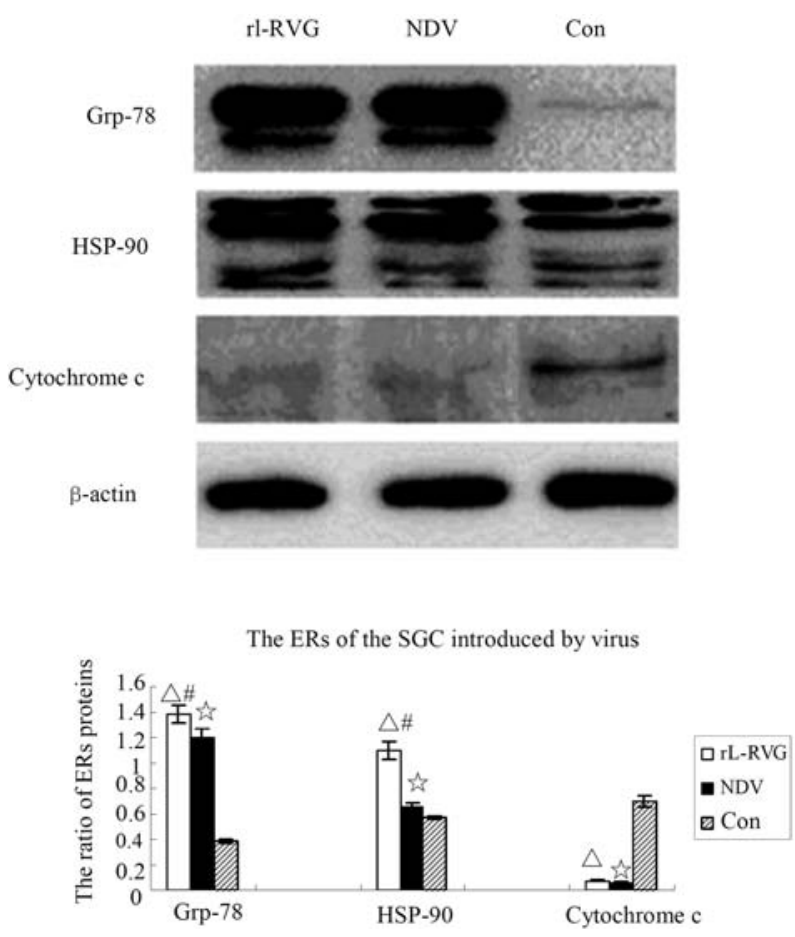

Figure 6. The expression of virus-induced endoplasmic reticulum stressassociated proteins in the SGC cells. The expression of ERs-associated proteins in the NDV-infected group significantly differed compared with that of the control group $(\mathrm{p}<0.05)$ and the expression of these proteins in the rL-RVG-infected group significantly differed compared with that of the control group $\left({ }^{\mathrm{p}} \mathrm{p}<0.05\right)$. A significant difference $\left({ }^{\circ} \mathrm{p}<0.05\right)$ in the expression of these proteins was observed between the rL-RVG-infected group and the NDV-infected group. In contrast, no significant difference in cytochrome $c$ levels was observed between the rL-RVG- and NDV-infected groups. 
A
G+3Ma rl-RVG N+3Ma NDV
$3 \mathrm{Ma} \quad \mathrm{Con}$
G+3Ma rl-RVG N+3Ma NDV $3 \mathrm{Ma}$
Con
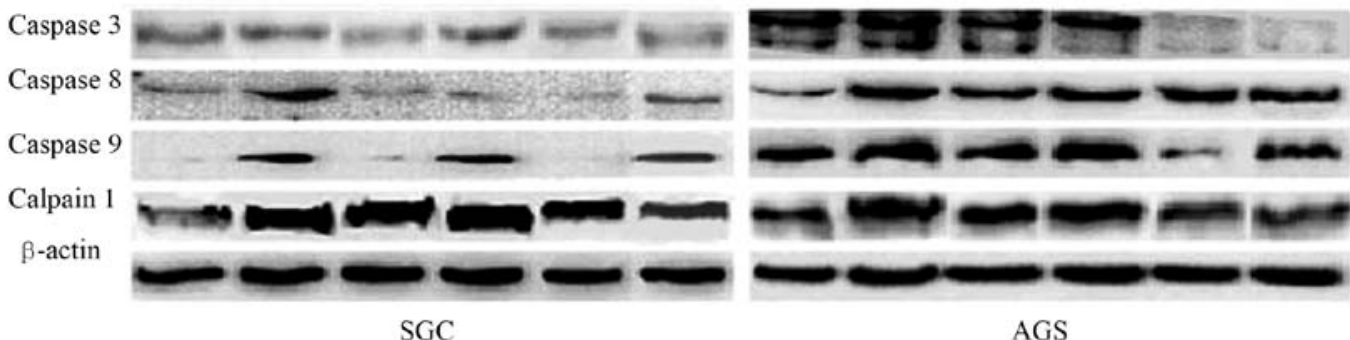

AGS

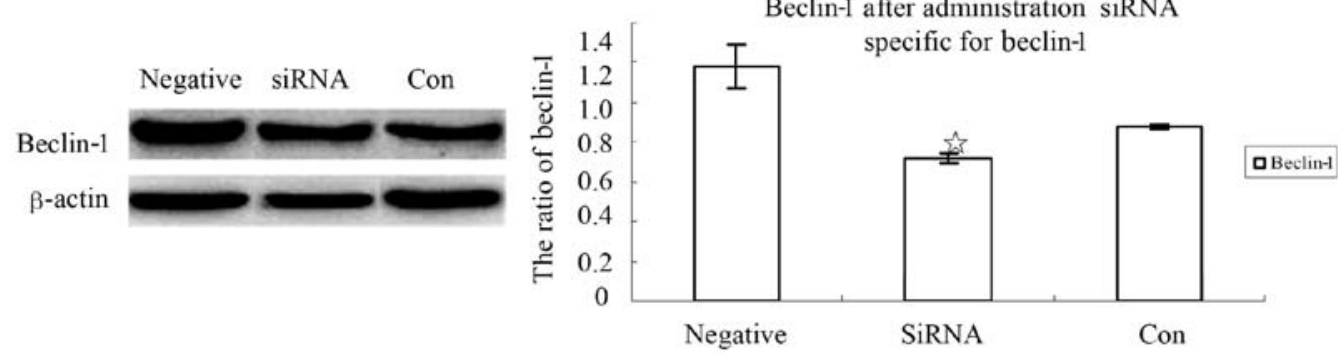

C

\section{$\mathrm{G}+\mathrm{Si} \quad \mathrm{rl}-\mathrm{RVG} \quad \mathrm{N}+\mathrm{Si} \quad \mathrm{NDV} \quad \mathrm{Con}$}

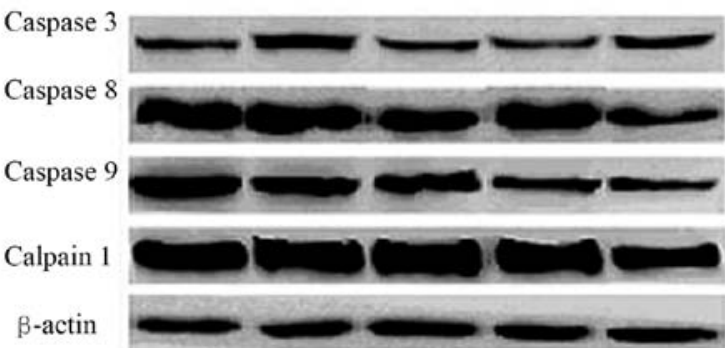

$\mathrm{G}+\mathrm{Si} \quad \mathrm{rl}-\mathrm{RVG} \quad \mathrm{N}+\mathrm{Si} \quad \mathrm{NDV} \quad \mathrm{Con}$

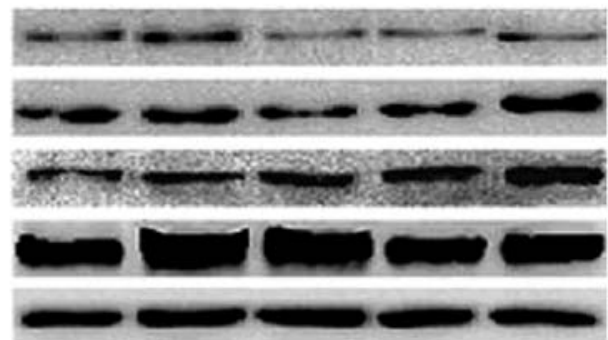

Figure 7. The contribution of downregulated autophagy to the expression of apoptosis-associated proteins in SGC and AGS cells after infection. (A) Apoptosisassociated protein expression after 3-MA treatment. The expression of the apoptosis-associated proteins caspase 3, 8 and 9 and calpain- 1 decreased in cells after 3-MA treatment compared with the cells without 3-MA treatment, and the above proteins were more strongly expressed in the rL-RVG-infected groups compared with the NDV-infected groups. (B) The expression of beclin-1 in cells. After administering beclin-1-specific siRNA, the expression of the beclin-1 protein decreased. (C) Apoptosis-associated protein expression after siRNA treatment. The expression of the apoptosis-associated proteins caspase 3, 8 and 9 and calpain 1 decreased in cells after beclin-1-specific siRNA treatment compared to those cells without siRNA treatment. These proteins were more strongly expressed in the rL-RVG-infected groups compared with the NDV-infected groups.

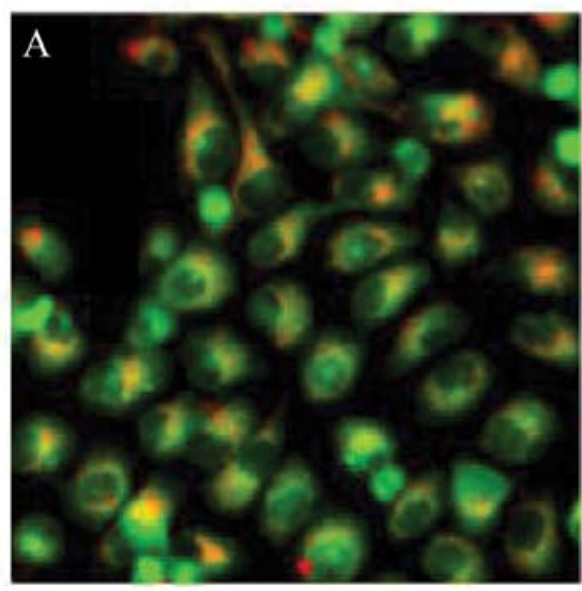

rl-RVG

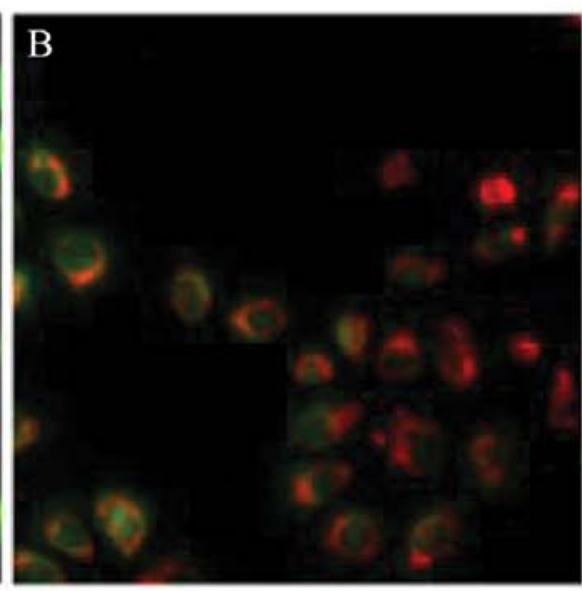

NDV

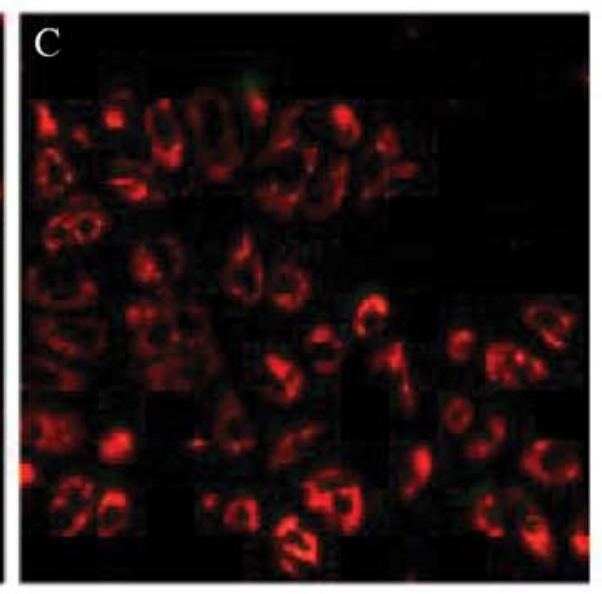

Con

Figure 8. NDV and rL-RVG infection induced MMP collapse in SGC cells. (A) rL-RVG-infected group, (B) NDV-infected group, and (C) control group. A greater number of dysfunctional mitochondria are present in rL-RVG-infected cells than in NDV-infected cells, and the control group has few dysfunctional mitochondria compared with the NDV-infected group. 
and calpain 1, and the results were similar to the 3-MA treatment experiment, as shown in Fig. 7C.

NDV and rL-RVG induce mitochondrial dysfunction. Mitochondria have essential roles in autophagy (31). We monitored the MMP with JC-1 staining. The greater the intensity of green in a cell, the more dysfunctional the mitochondria are. We found that the red fluorescence intensity decreased and the green fluorescence intensity increased in these cells. The ratio of red to green significantly decreased in the NDV- and rL-RVG-infected groups compared with the control group, and the ratio of red to green the in the rL-RVG-infected group decreased more than that in NDV-infected group, as shown in Fig. 8.

\section{Discussion}

NDV, which is a member of the oncolytic virus family, has the ability to inhibit malignant cells via multiple mechanisms (15). In recent decades, NDV has been shown to induce tumor cell death via its oncolytic effects (9). NDV can also induce the immune system to eliminate tumor cells (6), and NDV can infect tumor cells more effectively compared with normal cells (12). The rL-RVG virus spreads more easily within cells (26), and RVG has a potential oncolytic effect $(13,14)$; therefore, we propose that the recombinant virus rL-RVG has much more antitumor potency.

In the present study, we found that rL-RVG caused stomach adenocarcinoma SGC-7901 and AGS cell death, which is consistent with previous studies (27). Interestingly, in addition to apoptosis, both NDV and rL-RVG can induce autophagy, ERs and mitochondrial dysfunction. The results of the present study indicated that the net effects of autophagy, mitochondrial dysfunction and ERs contribute to tumor cell death. We considered that the observed mitochondrial dysfunction, ERs, autophagy, and apoptosis, indicate possible cross-talk with other pathways.

The autophagy pathway cross-talks with the apoptosis pathway; virus-induced autophagy can also contribute to apoptosis (32). Autophagy might also be a mechanism that contributes to virus-induced cell death (33). Although autophagy can promote tumor survival in some cases $(29,34)$, autophagy can also be fatal to malignant cells (35). Autophagy and apoptosis work together in multiple ways to determine the fate of tumor cells $(28,36)$. In the present study, both autophagy and apoptosis increased in the cells after viral infection. In the last decade, many researchers have confirmed that Bcl-2 plays an important role in both apoptosis and autophagy (37-39). Beclin-1 has an N-terminal BH3 domain, which this protein a subgroup of the Bcl-2 family $(39,40)$; therefore, beclin-1 can participate in the activity of the $\mathrm{Bcl}-2 / \mathrm{Bcl}-\mathrm{xL}$ complex and inhibit the formation of autophagosomes (41). We found that the virus-infected cells showed increase beclin-1 expression, thus decreasing the interaction between Beclin-1 and $\mathrm{Bcl}-2 / \mathrm{Bcl}-\mathrm{xL}$ and promoting autophagy and apoptosis. In addition, caspase 8 and caspase 12 play important roles in autophagy $(41,42)$. We also found that the expression of apoptosis-associated proteins increased in cells after viral infection. We suggest that rL-RVG and NDV cause tumor cell death via both autophagy and apoptosis.
Autophagy and ERs are related (43); both excess autophagy and excess ERs can cause cell death (44), and both moderate autophagy and moderate ERs are adaptive mechanisms when cells are under severe stress (45). Autophagy can recycle the organelles and provide the basic energy and material for cell survival $(16,46)$. In addition, Meng et al (47) and Meng et al (48), reported that autophagy can enhance NDV replication in tumor cells. Considering that NDV and rL-RVG introduced massive autophagy in the present study, we propose that the autophagy induced by NDV and rL-RVG allowed the viruses to increase replication and that these increased amounts of the viruses induced even more autophagy, thus becoming a positive feedback loop, with more and more virus initiating the unfolded protein response and causing ERs. Finally, autophagy and ERs reach a certain threshold, inducing cell death.

Additionally, autophagy and mitochondrial dysfunction work together to cause cell death. Mitochondria contribute to autophagy during cell death and disease by the mitochondrial permeability transition pathway $(46,49)$ and by reactive oxygen species (ROS) generation (50). The protein calpain, which is a member of the calmodulin family, can degrade ATG-5, and cleaved ATG-5 can anchor to mitochondria, causing cytochrome $c$ release, followed by mitochondrial dysfunction (30). In the present study, we found that the viruses caused excess autophagy and mitochondrial dysfunction, indicating that these viruses participate in cell death. The above results suggest that autophagy and mitochondrial dysfunction contribute to cell death. Although autophagy dysfunction may result in abnormal mitochondrial function (51), further experiments will be required to establish crosstalk among autophagy, mitochondria and oxidative stress pathways.

In conclusion, this study demonstrated that NDV and rL-RVG induce stomach adenocarcinoma cell death via autophagy and apoptosis, in association with ERs and mitochondrial dysfunction. Cell death may involve multiple pathways. Although the causal relations among autophagy, apoptosis and ERs remain unclear, rL-RVG may become a powerful candidate for antitumor treatments.

\section{Acknowledgements}

The authors would like to thank Professor Zhigao $\mathrm{Bu}$ and Dr Jinying Ge from the State Key Laboratory of Veterinary Biotechnology, Harbin Veterinary Research Institute, Chinese Academy of Agricultural Sciences, Harbin, China for supplying us with the recombinant Newcastle disease. The authors would also like to thank Dr Zhijian Zhang and Aihua Gong from Jiangsu University (Jiangsu, China) for kindly providing suggestions for the experiments that were performed. This study was supported by the Social Development Technological Support Projects of Zhenjiang, Jiangsu, China (grant no. SH2014046).

\section{References}

1. Chen J, Shen W, Xia J, Xu R, Zhu M and Xu M: Effect of S-1 maintenance chemotherapy following DCF regimen in patients with advanced gastric cancer. Nan Fang Yi Ke Da Xue Xue Bao 34: 1057-1060, 2014 (In Chinese). 
2. Khalighinejad N, Hariri H, Behnamfar O, Yousefi A and Momeni A: Adenoviral gene therapy in gastric cancer: A review. World J Gastroenterol 14: 180-184, 2008.

3. Janke M, Peeters B, de Leeuw O, Moorman R, Arnold A, Fournier P and Schirrmacher V: Recombinant Newcastle disease virus (NDV) with inserted gene coding for GM-CSF as a new vector for cancer immunogene therapy. Gene Ther 14: 1639-1649, 2007.

4. Beutner U, Lorenz U, Illert B, Rott L, Timmermann W, Vollmers HP, Müller-Hermelink HK, Thiede A and Ulrichs K: Neoadjuvant therapy of gastric cancer with the human monoclonal IgM antibody SC-1: Impact on the immune system. Oncol Rep 19: 761-769, 2008.

5. Garg AD and Agostinis P: ER stress, autophagy and immunogenic cell death in photodynamic therapy-induced anti-cancer immune responses. Photochem Photobiol Sci 13: 474-487, 2014.

6. Hossain A, Radwan FF, Doonan BP, God JM, Zhang L, Bell PD and Haque A: A possible cross-talk between autophagy and apoptosis in generating an immune response in melanoma. Apoptosis 17: 1066-1078, 2012.

7. Puhlmann J, Puehler F, Mumberg D, Boukamp P and Beier R: Racl is required for oncolytic NDV replication in human cancer cells and establishes a link between tumorigenesis and sensitivity to oncolytic virus. Oncogene 29: 2205-2216, 2010.

8. Pecora AL, Rizvi N, Cohen GI, Meropol NJ, Sterman D, Marshall JL, Goldberg S, Gross P, O'Neil JD, Groene WS, et al: Phase I trial of intravenous administration of PV701, an oncolytic virus, in patients with advanced solid cancers. J Clin Oncol 20 2251-2266, 2002.

9. Sinkovics JG and Horvath JC: Newcastle disease virus (NDV): Brief history of its oncolytic strains. J Clin Virol 16: 1-15, 2000 .

10. Yang S, Liu W, Cui H, Sun S and Wang J: In vitro induction of apoptosis in tumor cells by inactivated NDV and IAV. Cancer Biother Radiopharm 22: 200-205, 2007.

11. Yaacov B, Eliahoo E, Lazar I, Ben-Shlomo M, Greenbaum I, Panet A and Zakay-Rones Z: Selective oncolytic effect of an attenuated Newcastle disease virus (NDV-HUJ) in lung tumors. Cancer Gene Ther 15: 795-807, 2008.

12. Lam HY, Yeap SK, Rasoli M, Omar AR, Yusoff K, Suraini AA and Alitheen NB: Safety and clinical usage of newcastle disease virus in cancer therapy. J Biomed Biotechnol 2011: 718710, 2011.

13. Lay S, Préhaud C, Dietzschold B and Lafon M: Glycoprotein of nonpathogenic rabies viruses is a major inducer of apoptosis in human jurkat T cells. Ann NY Acad Sci 1010: 577-581, 2003.

14. Préhaud C, Lay S, Dietzschold B and Lafon M: Glycoprotein of nonpathogenic rabies viruses is a key determinant of human cell apoptosis. J Virol 77: 10537-10547, 2003.

15. Vähä-Koskela MJ, Heikkilä JE and Hinkkanen AE: Oncolytic viruses in cancer therapy. Cancer Lett 254: 178-216, 2007.

16. Klionsky DJ and Emr SD: Autophagy as a regulated pathway of cellular degradation. Science 290: 1717-1721, 2000.

17. Rubinsztein DC, Codogno P and Levine B: Autophagy modulation as a potential therapeutic target for diverse diseases. Nat Rev Drug Discov 11: 709-730, 2012.

18. Carroll RG and Martin SJ: Autophagy in multiple myeloma: What makes you stronger can also kill you. Cancer Cell 23: 425-426, 2013.

19. Kroemer G and Levine B: Autophagic cell death: The story of a misnomer. Nat Rev Mol Cell Biol 9: 1004-1010, 2008.

20. Ahn JH and Lee M: Autophagy-dependent survival of mutant B-Raf melanoma cells selected for resistance to apoptosis induced by inhibitors against oncogenic B-Raf. Biomol Ther (Seoul) 21: 114-120,2013

21. Martín V, Sanchez-Sanchez AM, Puente-Moncada N, GomezLobo M, Alvarez-Vega MA, Antolín I and Rodriguez C: Involvement of autophagy in melatonin-induced cytotoxicity in glioma-initiating cells. J Pineal Res 57: 308-316, 2014.

22. Xu ZX, Liang J, Haridas V, Gaikwad A, Connolly FP, Mills GB and Gutterman JU: A plant triterpenoid, avicin D, induces autophagy by activation of AMP-activated protein kinase. Cell Death Differ 14: 1948-1957, 2007.

23. Cheng J, Wei HL, Chen J and Xie B: Antitumor effect of arsenic trioxide in human K562 and K562/ADM cells by autophagy. Toxicol Mech Methods 22: 512-519, 2012.

24. Kulich I and Žárský V: Autophagy-related direct membrane import from ER/cytoplasm into the vacuole or apoplast: A hidden gateway also for secondary metabolites and phytohormones? Int J Mol Sci 15: 7462-7474, 2014
25. Shailasree S, Venkataramana M, Niranjana SR and Prakash HS: Cytotoxic effect of p-coumaric acid on neuroblastoma, N2a cell via generation of reactive oxygen species leading to dysfunction of mitochondria inducing apoptosis and autophagy. Mol Neurobiol 51: 119-130, 2015.

26. Ge J, Wang X, Tao L, Wen Z, Feng N, Yang S, Xia X, Yang C, Chen $\mathrm{H}$ and $\mathrm{Bu} \mathrm{Z}$ : Newcastle disease virus-vectored rabies vaccine is safe, highly immunogenic, and provides long-lasting protection in dogs and cats. J Virol 85: 8241-8252, 2011

27. Yan Y, Liang B, Zhang J, Liu Y and Bu X: Apoptotic induction of lung adenocarcinoma A549 cells infected by recombinant RVG Newcastle disease virus (rLRVG) in vitro. Mol Med Rep 11: 317-326, 2015.

28. Chen W, Sun Y, Liu K and Sun X: Autophagy: A double-edged sword for neuronal survival after cerebral ischemia. Neural Regen Res 9: 1210-1216, 2014.

29. Gong A, Ye S, Xiong E, Guo W, Zhang Y, Peng W, Shao G, Jin J, Zhang Z, Yang J, et al: Autophagy contributes to ING4-induced glioma cell death. Exp Cell Res 319: 1714-1723, 2013.

30. Yousefi S, Perozzo R, Schmid I, Ziemiecki A, Schaffner T, Scapozza L, Brunner T and Simon HU: Calpain-mediated cleavage of Atg5 switches autophagy to apoptosis. Nat Cell Biol 8: 1124-1132, 2006.

31. Yuzefovych LV, LeDoux SP, Wilson GL and Rachek LI: Mitochondrial DNA damage via augmented oxidative stress regulates endoplasmic reticulum stress and autophagy: Crosstalk, links and signaling. PLoS One 8: e83349, 2013.

32. Zorn U, Dallmann I, Grosse J, Kirchner H, Poliwoda H and Atzpodien J: Induction of cytokines and cytotoxicity against tumor cells by Newcastle disease virus. Cancer Biother 9: 225-235, 1994

33. Tsuchihara K, Fujii S and Esumi H: Autophagy and cancer: Dynamism of the metabolism of tumor cells and tissues. Cancer Lett 278: 130-138, 2009.

34. Kimura T, Takabatake Y, Takahashi A and Isaka Y: Chloroquine in cancer therapy: A double-edged sword of autophagy. Cancer Res 73: 3-7, 2013.

35. Mariño G, Martins I and Kroemer G: Autophagy in Ras-induced malignant transformation: Fatal or vital? Mol Cell 42: 1-3, 2011.

36. Gong JS and Kim GJ: The role of autophagy in the placenta as a regulator of cell death. Clin Exp Reprod Med 41: 97-107, 2014.

37. Luo S and Rubinsztein DC: BCL2L11/BIM: A novel molecular link between autophagy and apoptosis. Autophagy 9: 104-105, 2013.

38. Saeki K, Yuo A, Okuma E, Yazaki Y, Susin SA, Kroemer G and Takaku F: Bcl-2 down-regulation causes autophagy in a caspaseindependent manner in human leukemic HL60 cells. Cell Death Differ 7: 1263-1269, 2000.

39. Lomonosova $\mathrm{E}$ and Chinnadurai G: $\mathrm{BH} 3$-only proteins in apoptosis and beyond: An overview. Oncogene 27 (Suppl 1): S2-S19, 2008

40. Pattingre S, Tassa A, Qu X, Garuti R, Liang XH, Mizushima N Packer M, Schneider MD and Levine B: Bcl-2 antiapoptotic proteins inhibit Beclin 1-dependent autophagy. Cell 122: 927-939, 2005.

41. Cho DH, Jo YK, Hwang JJ, Lee YM, Roh SA and Kim JC: Caspase-mediated cleavage of ATG6/Beclin-1 links apoptosis to autophagy in HeLa cells. Cancer Lett 274: 95-100, 2009.

42. Lin CJ, Lee CC, Shih YL, Lin CH, Wang SH, Chen TH and Shih CM: Inhibition of mitochondria- and endoplasmic reticulum stress-mediated autophagy augments temozolomide-induced apoptosis in glioma cells. PLoS One 7: e38706, 2012.

43. Jheng JR, Ho JY and Horng JT: ER stress, autophagy, and RNA viruses. Front Microbiol 5: 388, 2014.

44. Digaleh H, Kiaei M and Khodagholi F: Nrf2 and Nrf1 signaling and ER stress crosstalk: Implication for proteasomal degradation and autophagy. Cell Mol Life Sci 70: 4681-4694, 2013.

45. Tian J, Hu X and Qu Q: Effect and mechanism of endoplasmic reticulum stress on cisplatin resistance in ovarian carcinoma] Zhonghua Zhong Liu Za Zhi 36: 324-328, 2014 (In Chinese).

46. Suzuki SW, Onodera J and Ohsumi Y: Starvation induced cell death in autophagy-defective yeast mutants is caused by mitochondria dysfunction. PLoS One 6: e17412, 2011.

47. Meng C, Zhou Z, Jiang K, Yu S, Jia L, Wu Y, Liu Y, Meng S and Ding C: Newcastle disease virus triggers autophagy in U251 glioma cells to enhance virus replication. Arch Virol 157: 1011-1018, 2012. 
48. Meng G, Xia M, Wang D, Chen A, Wang Y, Wang H, Yu D and Wei J: Mitophagy promotes replication of oncolytic Newcastle disease virus by blocking intrinsic apoptosis in lung cancer cells. Oncotarget 5: 6365-6374, 2014.

49. Marzetti E, Csiszar A, Dutta D, Balagopal G, Calvani R and Leeuwenburgh C: Role of mitochondrial dysfunction and altered autophagy in cardiovascular aging and disease: From mechanisms to therapeutics. Am J Physiol Heart Circ Physiol 305 H459-H476, 2013
50. Wu JJ, Quijano C, Chen E, Liu H, Cao L,Fergusson MM, Rovira II, Gutkind S, Daniels MP, Komatsu M, et al: Mitochondrial dysfunction and oxidative stress mediate the physiological impairment induced by the disruption of autophagy. Aging (Albany, NY) 1: 425-437, 2009.

51. Lee J, Giordano S and Zhang J: Autophagy, mitochondria and oxidative stress: Cross-talk and redox signalling. Biochem J 441: 523-540, 2012. 